Acta Theriologica 37 (3): 259 - 270, 1992.

PL ISSN $0001-7051$

\title{
Reproductive characteristics of feral pigs in New Zealand
}

\author{
Ryszard M. DZIĘCIOŁOWSKI, Colin M. H. CLARKE \\ and Chris M. FRAMPTON
}

\begin{abstract}
Dzięciołowski R. M., Clarke C. M. H. and Frampton C. M. 1992. Reproductive characteristics of feral pigs in New Zealand. Acta theriol. 37: $259-270$.

Breeding was studied in feral pigs Sus scrofa Linnaeus, 1758 inhabiting the northern part of the South Island, New Zealand. In a sample of 1,117 female pigs $50.4 \%$ showed evidence (pregnancy or lactation) that they were breeding. There was no statistically significant regional variation in the breeding status of females. Breeding occurred throughout the year with birth peaks in July-November and March. Among 101 females $5-8$ months old, $30(29.7 \%)$ were pregnant. The oldest breeding sow was 14 years old. Breeding females up to 17 months old were significantly heavier than non-breeding females, but the difference ceased to be significant for older animals. Pregnant females averaged 6.2 foetuses (range $1-11$ ). Lactating females had on average 5.4 teats extended (range $1-12$ ). For areas where pigs are considered a pest species a simulation model predicted a population recovery time of 30 months from a $70 \%$ kill.

Department of Forest Zoology and Wildlife Management, Warsaw Agricultural University, Rakowiecka 26/30, 02-528 Warsaw, Poland (RMD); Forest Research Institute, P.O.Box 31-011, Christchurch, New Zealand (CMHC and CMF)

Key words: feral pigs, reproduction, New Zealand
\end{abstract}

\section{Introduction}

Feral pigs Sus scrofa Linnaeus, 1758 are widespread in the northern South Island, New Zealand, and are a popular recreational hunting resource. The annual harvest in 1988 by hunters using dogs was estimated at $40,000-50,000$, or 25 35 per hunter (Clarke 1991). Pig populations are mostly stable or declining (Clarke and Dzięciołowski 1991); the highest densities are those sustaining annual hunter harvests of 20 pigs $/ \mathrm{km}^{2}$ (Clarke and Dzięciołowski 1991) or reaching an estimated unharvested population of $43 \mathrm{pigs} / \mathrm{km}^{2}$ (McIlroy 1989). Hunter harvests have declined substantially (by $60 \%$ in high density areas) since the 1970 s and are now mostly comprised of animals less than 1 year old (Dzięciołowski and Clarke 1989). However, local pig numbers fluctuate seasonally with the breeding season and with hunting pressure which can be uneven because of difficult or denied access to hunting areas. In some areas effective levels of control may not be achieved solely by hunting and other methods including poisoning may be required.

The aim of this study is to describe the breeding characteristics of feral pigs and to use these data to simulate potentials for population increase as a basis for 
determining the level of population reduction necessary to establish effective population control. Such control work would be aimed at effective control of diseased pig populations and those threatening important conservation areas.

The study area was divided into four regions (Nelson, Marlborough, North Canterbury, and South Canterbury) based on both provincial boundaries and physical boundaries between pig populations (Fig. 1).

\section{Methods}

Data collected on 1,117 female pigs harvested by hunters between July 1986 and October 1987 included kill site, date killed, field-dressed weight (gutted, reproductive tract removed, heart, lung, head and hocks attached), pregnancy, number of foetuses, lactation, and number of teats extended. About $90 \%$ of these data were recorded by hunters with the authors recording the remainder. All pigs were eviscerated to provide standard field-dressed weights, according to game meat industry requirements when carcasses were sold. Hunters assessed reproductive condition using instructions provided by the authors. Weaning ages of piglets were determined for 9 captive feral-born sows kept within a 26 ha semifree range site. The age of pigs was assessed in the laboratory using either tooth eruption and wear (juveniles) or dental cementum layering in molars (older animals) (Clarke et al., in press). Teeth of known-age animals were used to calibrate these aging techniques to provide accurate ages $( \pm 1$ month for pigs aged $<30$ months; \pm 6 months for pigs aged $>30$ months).

The minimum age and size at which reproduction occurs in females was determined from pigs aged less than 1 year. Four known-age females born in captivity to feral-born mothers were also studied. These individuals were killed and examined internally at ages of $6-7$ months. All captive females were housed with similarly aged males from age 3 months, though 7 month-old males were introduced when the females were aged 5 months. Although it was intended that captive pigs should receive a balanced diet, the initial supply of a diet lacking in protein resulted in pigs receiving inadequate food for growth. Although a more balanced diet was subsequently provided, the growth of the captive females remained retarded compared to the harvested feral animals.

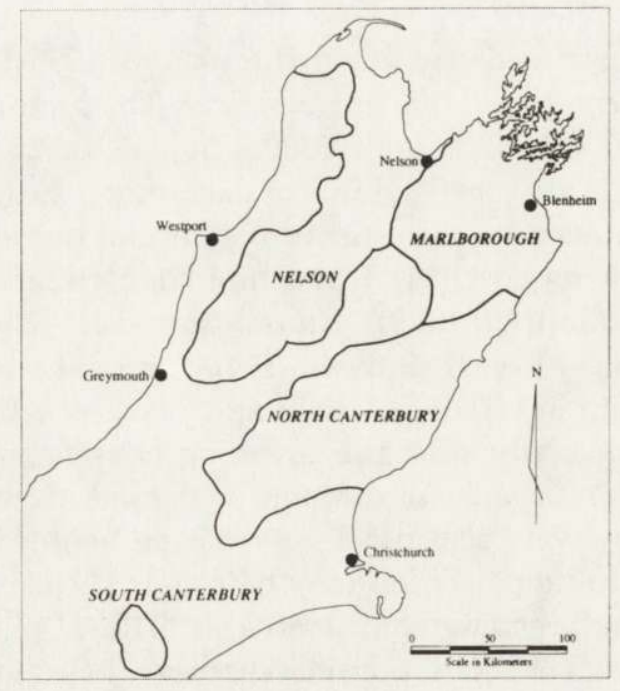

Fig. 1. The study area with regional boundaries. 
Breeding frequency was determined for 2 years from 11 captive feral-born adult females aged between 1 and 3 years. Breeding season was determined both from records of harvested pregnant and lactating females, and from the age of each pig when killed, from which an actual birth date was calculated. This was done by subtracting the age of the pig when killed from the kill date. Analyses were by Chi-square test of independence, except for litter size, number of teats, and weight comparisons, where parametric analysis of variance was used. Litter size and teat number data were transformed by square-root prior to analysis.

In modelling these data age-specific survival was calculated empirically from the age structure of a harvested population of pigs from the study area (Dzięciołowski and Clarke 1989). The age structure of the harvested sample indicated a heavy impact from hunting, with $70 \%$ aged less than 1 year and few animals older than 2 years. Natural (non-hunting) mortality is unknown for New Zealand feral pig populations so the trend of decreased survival with age was conservatively estimated from hunting mortality (Dzięciołowski and Clarke 1989) to reflect both components of mortality.

Given the demographic parameters of birth rate, age-specific survival and duration of pregnancy the exponential rate of increase $(r)$ was calculated for a pig population with no density dependent factors using a Leslie matrix manipulation (Leslie 1945). This $r$ was then used with a hypothetical carrying capacity $(k)$ to model the population growth curve. The model used was the $\Theta$-logistic model (Gilpen et al. 1976) with $\Theta$ set to 2 to provide likely maximum recovery times (Barlow and Clout 1983. The hunting pressure required to keep the population near equilibrium was assumed to be densiy dependent, hence the entire sigmoid curve was assured to model the current status. Following a coninuous population growth to equilibrium, the numbers were then manipulated to simulate $70 \%$, $80 \%, 90 \%$ and $95 \%$ reductions as might result from a single control operation. The times for subsequent recovery to $95 \%$ of original numbers were then estimated.

\section{Results}

\section{Breeding status}

Of the 1,117 female pigs studied, $334(29.9 \%)$ were pregnant and $229(20.5 \%)$ were lactating, indicating that about half $(50.4 \%)$ were involved in breeding. When femsles below breeding age (see later) were excluded, the percentage breeding increased slightly to $52.9 \%$. The breeding status of females varied significantly with region $\left(\chi_{6}^{2}=24.085, p<0.001\right)$ with the highest proportion of breeding females in the Nelson region (60.9\%) and the lowest in North Canterbury (48.6\%) (Fig. 2).

\section{Breeding season}

Breeding occurs throughout the year as evidenced by calculated dates of birth (Fig. 3). The main birth period extends from July to November (i.e., late winter sprirg) with another peak in March. Relatively few births occurred during April - June (autumn). A similar seasonal distribution of births was also shown from pregiancy and lactation data (Fig. 4). Peaks of pregnancy occurred in July Augtst, while the peak in lactation occurred in October, thus indicating that Sept:mber was the principal birth month.

\section{Breeding frequency}

Tie 11 captive feral females produced a mean of 1.8 litters annually. However, 4 of the 9 females that produced 2 litters in both years also commenced a third 

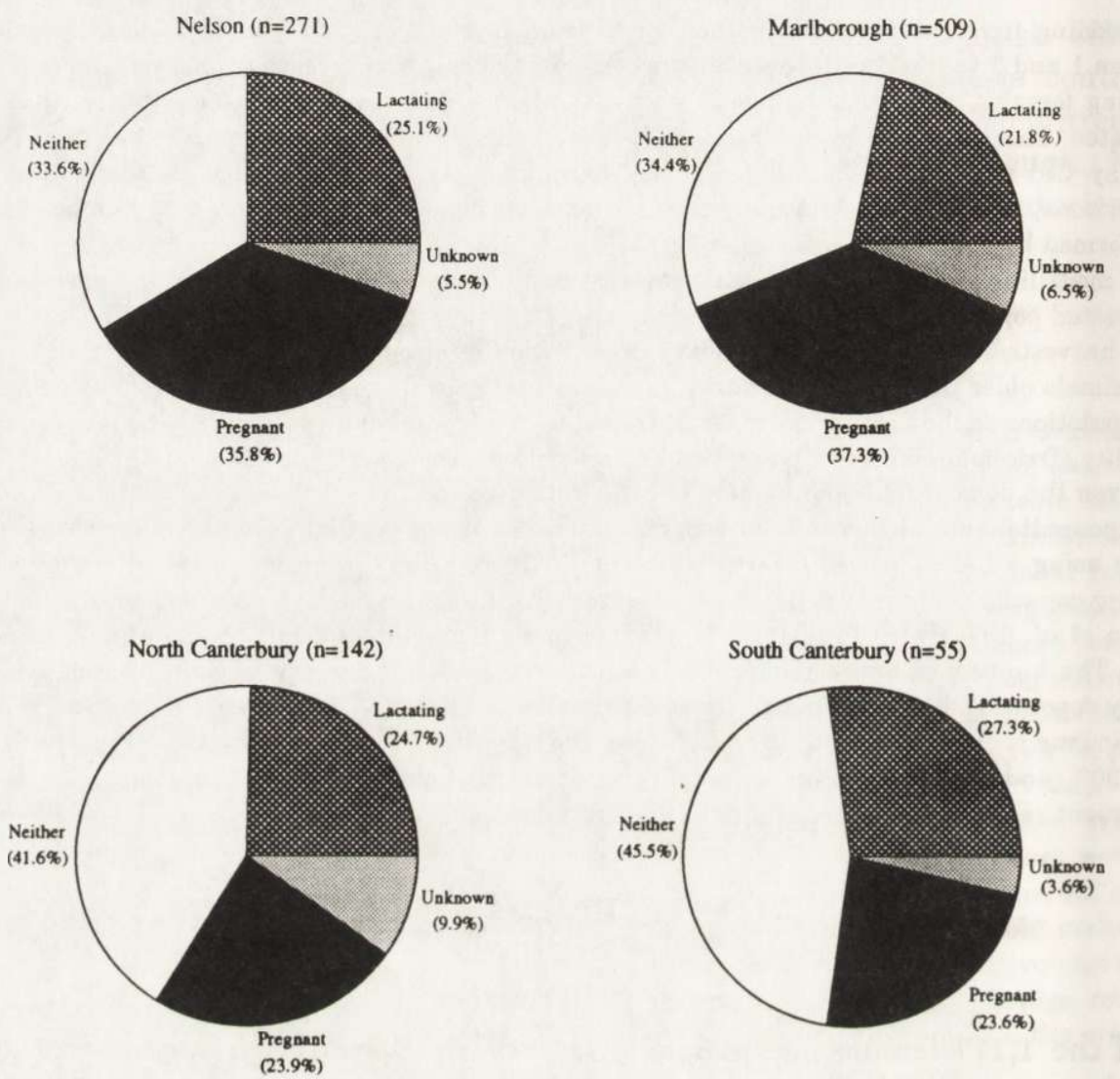

Fig. 2. Regional percentages of female feral pigs pregnant, lactating, neither preganat nor lactating, and unclassified.

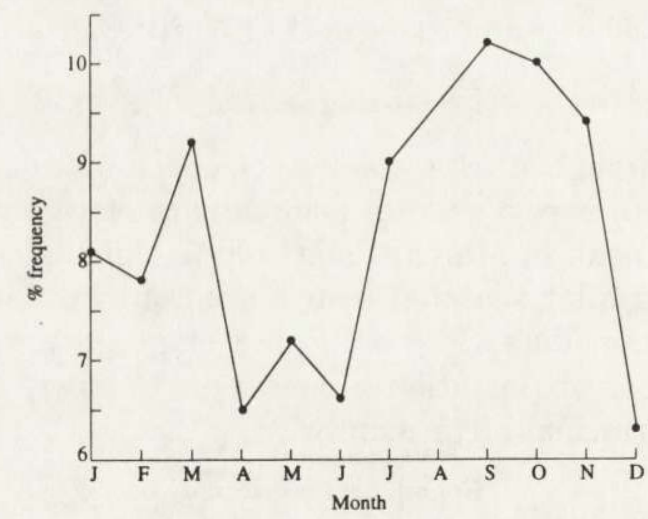

Fig. 3. Percentage frequency of female feral pig births by monyh. Data based on age of each pig when killed, back-dated to give birth month. 
Table 1. Proportion of pregnant and lactating feral pigs with mean number of foetuses and teats extended in 6 monthly age classes. Mid point of age classes shown.

\begin{tabular}{|c|c|c|c|c|c|c|c|}
\hline \multirow{2}{*}{$\begin{array}{c}\text { Age } \\
\text { (in moniths) }\end{array}$} & \multirow{2}{*}{$\mathrm{n}$} & \multirow{2}{*}{$\begin{array}{l}\text { Number } \\
\text { pregnant }\end{array}$} & \multirow{2}{*}{$\begin{array}{l}\text { Mean number } \\
\text { of foetuses }\end{array}$} & \multirow{2}{*}{$\begin{array}{l}\text { Number } \\
\text { lactating }\end{array}$} & \multirow{2}{*}{$\begin{array}{l}\text { Mean number } \\
\text { of teats extended }\end{array}$} & \multicolumn{2}{|c|}{ Breeding sows } \\
\hline & & & & & & $\mathrm{n}$ & $\%$ \\
\hline 3 & 127 & 6 & 5.3 & 1 & 6.0 & 7 & 5.5 \\
\hline 9 & 175 & 50 & 5.6 & 13 & 5.0 & 63 & 36.0 \\
\hline 15 & 174 & 46 & 5.9 & 48 & 5.1 & 94 & 54.0 \\
\hline 21 & 99 & 34 & 6.2 & 25 & 5.4 & 59 & 60.0 \\
\hline 27 & 109 & 38 & 6.4 & 33 & 4.9 & 71 & 65.1 \\
\hline 33 & 144 & 23 & 6.4 & 13 & 6.1 & 46 & 31.9 \\
\hline 39 & 39 & 9 & 6.7 & 16 & 5.5 & 25 & 64.1 \\
\hline 45 & 32 & 12 & 7.9 & 10 & 6.2 & 22 & 68.8 \\
\hline 51 & 20 & 9 & 6.2 & 5 & 5.4 & 14 & 70.0 \\
\hline 57 & 20 & 6 & 7.5 & 8 & 5.9 & 14 & 70.0 \\
\hline 63 & 11 & 4 & 6.2 & 4 & 5.5 & 8 & 72.7 \\
\hline 69 & 16 & 2 & 7.5 & 5 & 5.4 & 7 & 43.8 \\
\hline$>75$ & 24 & 5 & 3.3 & 8 & 3.5 & 13 & 54.1 \\
\hline
\end{tabular}

Table 2. Mean weights (in kg) of breeding (pregnant and lactating) and nonbreeding female feral pigs aged $5-8$ months (sample sizes shown in brackets).

\begin{tabular}{lcccc}
\hline Age (months) & 5 & 6 & 7 & 8 \\
\hline Breeding & $24.9(2)$ & $23.8(8)$ & $24.7(7)$ & $25.4(13)$ \\
Non-breeding & $16.6(12)$ & $17.3(26)$ & $19.1(11)$ & $21.0(22)$ \\
\hline
\end{tabular}

Fig. 4. Monthly percentage of female feral pigs

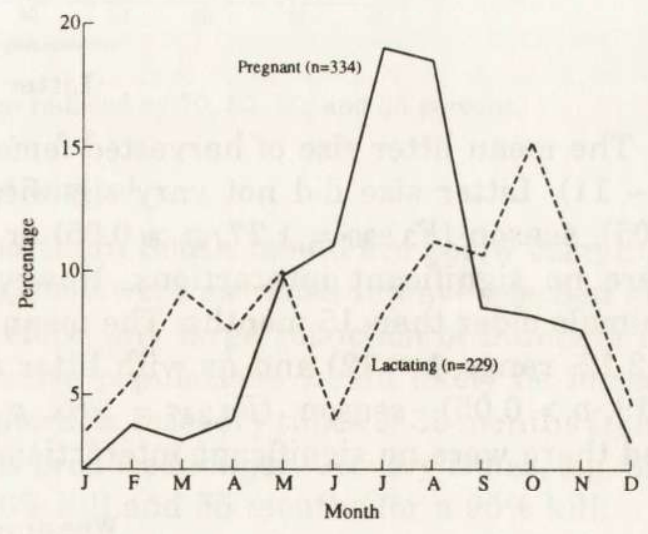
pregnant or lactating.

pregnancy within each year. A single pregnancy-birth-lactation cycle extended over approximately 5 months and those that had 3 pregnancies in a year produced 3 litters over 14 - 16 months. 


\section{Age of breeding females}

Table 1 shows the proportion of breeding females in six-monthly age classes. The youngest breeding females were aged 5 months $(n=2)$ and represented $14.3 \%$ of the females aged 5 months. Twenty-one per cent of females aged 5 and 6 months were breeding, $37.8 \%$ of those aged 7 and 8 months, and $63.9 \%$ of females aged 9 - 12 months. These percentages undoubtedly underestimate the actual numbers breeding as not all early pregnancies would have been detected by hunters. The oldest breeding female was 168 months old (14 years) and was the oldest pig recorded in the study area.

Comparison of body weights of breeding and non-breeding females aged $5-8$ months showed larger females bred earlier $\left(F_{1,92}=12.6, p<0.001\right.$, Table 2$)$. The mean dressed weights at which $5-8$ months old pigs became pregnant $(n=30)$ was $24.8 \mathrm{~kg}$ or $60.5 \%$ of the average dressed weight of adult ( $>2$ years) females (Dzięciołowski et al. 1990). Comparable non-breeding females $(n=71)$ in these age classes had an average dressed weight of $18.5 \mathrm{~kg}$. When the data for breeding and non-breeding females was extended and regrouped in $1-11,12-17,18$ 23 , and $>24$ month age classes, similar significant differences in dressed weight were shown for breeding and non-breeding females up to the $12-17$ month age class $\left(F_{1,297}=28.4, p<0.001\right)$, but the difference ceased to be significant for older age classes $\left(F_{1,384}=0.0, p>0.05\right)$.

Of the 4 captive females killed and examined when aged $6-7$ months, 2 were pregnant. Their dressed weights were 17.6 and $18.3 \mathrm{~kg}$, vs 15.5 and $16.8 \mathrm{~kg}$ for the two captive non-breeding females. These lower weights of captive breeding females compared to those of the harvested breeding females were apparently due to their inadequate diet in captivity that stunted their growth.

\section{Litter size}

The mean litter size of harvested females $(n=291)$ was $6.2(\mathrm{SD}=1.77$, range 1 - 11$)$. Litter size did not vary significantly with region $\left(F_{3,210}=0.8045, p>\right.$ $0.05)$, season $\left(F_{3,290}=1.77, p>0.05\right)$ or age $\left(F_{3,240}=1.66, p>0.05\right)$ and there were no significant interactions. However, the larger litters occurred only in animals older than 15 months. The mean numbers of teats extended was 5.4 (SD $=2.12$, range $1-12)$ and as with litter sizes did not vary with region $\left(F_{3,267}=\right.$ $1.19, p>0.05)$, season $\left(F_{3,247}=1.52, p>0.05\right)$ or age $\left(F_{3,241}=0.53, p>0.05\right)$ and there were no significant interactions.

\section{Weaning ages}

Few data were recorded on weaning ages of feral piglets, although hunters generally reported that piglets were weaned after reaching $1-2$ months of age. Six captive feral-born sows weaned their litters at $7-8$ weeks of age, two weaned theirs at 6 weeks of age, and a single sow weaned hers at 10 weeks. 


\section{Simulation of population increase}

Estimates used in the model are based on the present data and on the age/sex structure given in Dzięciołowski and Clarke (1989).

The following assumptions were made: (1) females mature sexually at 10 months, (2) all mature females breed every 5 months (i.e. time required for pregnancy, birth, weaning and commencement of another pregnancy), (3) average litter size of 6 (with a constant and equal sex ratio, Dzięciołowski and Clarke 1989 .

The model also assumes decreasing survival with age, i.e. $60 \%$ survival at 5 months, $40 \%$ at 10 months, $35 \%$ at 15 months, $30 \%$ at 20 months, $25 \%$ at 25 months, $20 \%$ at 30 months, $10 \%$ at 35 months, $5 \%$ at $40-60$ months, $2.5 \%$ at 60 -120 months and $0 \%$ beyond 120 months. From these data an exponential rate of increase $(r)$ was estimated at 0.90 .

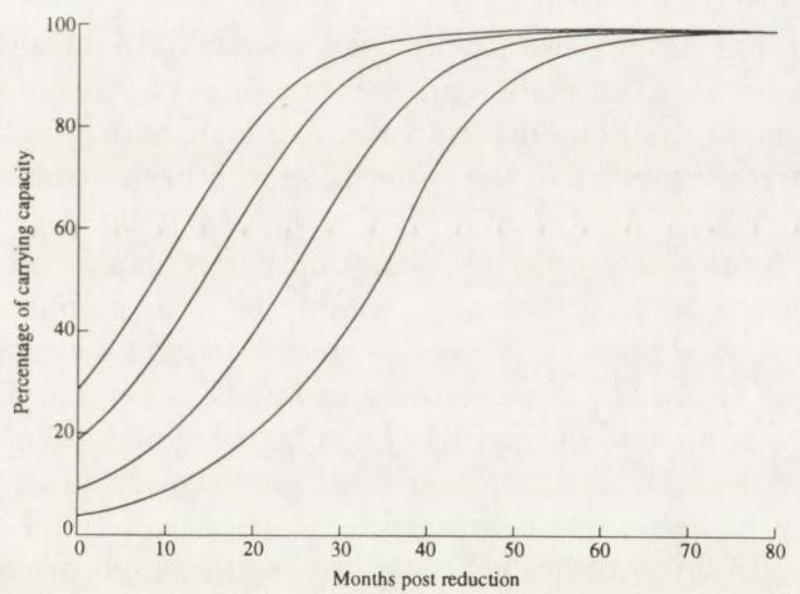

Fig. 5. Recovery rates for a pig population reduced by $70,80,90$, and 95 percent.

\section{Simulated control}

Because current pig densities in the northern South Island are below carrying capacty (Dzięciołowski and Clarke 1990), they were assumed to have reached an equilibrium with hunting pressure. Therefore, any large reduction of numbers is likely to result in rapid replacement because populations would likely be forced into asteeply erupting phase. The model predicts recovery times of 30 months from a $70 \%$ kill (Fig. 5). Higher percentage kills produced longer recovery times, e.g. 35 montis for a $80 \%$ kill, 45 months for a $90 \%$ kill and 55 months for a $95 \%$ kill.

\section{Discussion}

Comparison of these reproductive data with those of other feral pig populations show: that New Zealand feral pigs farrow earlier and more frequently than 
reported elsewhere. The youngest breeding female in our study was only 5 months old, compared to 9 months old in USA (Sweeney et al. 1979). Feral sows in California reach puberty at the age of $6-8$ months (Barrett 1978), whereas European wild boar generally do not begin to breed until they are yearlings (18 - 21 months) (Andrzejewski and Jezierski 1978), though in good years a small proportion of sows may breed when $8-10$ months old (Briedermann 1971, Stubbe and Stubbe 1977). Sexual maturity of feral pigs depends on body weight (Mc Ilroy 1990 ) with Australian feral sows breeding only when they reach $20-30 \mathrm{~kg}$, usually at about 7-12 months of age (cf 4-9 months in domestic pigs). In our field study only the larger sows began breeding at $5-8$ months, whereas the captive animals bred at lower weights. This suggests that the onset of breeding could be governed by minimum proportion of final body size, rather than actual body weight. Alternatively, the stresses of poor nutrition during captivity may have precipitated breeding at a lower weight threshold.

Because feral pigs have a gestation period of about 115 days (Henry 1968) and sows may be bred before the piglets are weaned, it is physiologically possible for sows to produce more than one litter a year. Some authors (e.g. Giffin 1978) have reported sows farrowing twice in the same 12 month period and our data showing some sows producing 3 litters over $14-16$ months may be close to the maximum productivity for feral Sus scrofa. This may be partly explained by low weaning ages, but an investigation of stomach contents of feral piglets in Australia has indicated earlier weaning ages to those reported, mostly at 4 weeks (Rathore 1988). On the other hand Giffin (1978) reported weaning ages ranging from five and one half weeks to five and one half months of age for feral piglets in Hawaii. Because average weaning ages in New Zealand feral pigs appear to be similar to those cited, there may be other explanations for high productivity. Early breeding, multiple litters, and large litters all contribute to this high productivity and may be the result of adaptation by feral pigs to specific New Zealand conditions. Particular light conditions and extended growing season in New Zealand have previously been suggested as reasons for early breeding in introduced chamois Rupicapra rupicapra (Bauer 1985).

We found that feral pigs in New Zealand bred throughout the year though mainly in winter/spring (July - November) and in autumn (March). This differs from Wodzicki (1950) who noted the main breeding season in New Zealand to be spring and summer. Elsewhere, feral pigs on Ossabaw Island (Louisiana) showed a similar winter/spring and autumn breeding season (I. L. Brisbin, pers. comm.) to that found in our study. In Pakistan most wild boars are born in the cool winter months (Smiet et al. 1979). In Hawaii the farrowing season occurs in winter-spring with farrowing being related to the rainy season which produces more abundant food resources (Giffin 1977). Converselly, Barrett (1978) found that feral hogs in California had no definite peak of farrowing, although there were two small increases in births in July (summer) and November (autumn). By comparison European wild boar normally breed once a year (gestation period 108-140 days, 
Asdell 1964) and most young are born in spring (March - May), although occasionally also in January, February and in summer. They are capable of producing two litters per year under zoo conditions and during years with excellent mast crops (Krupka 1989). However wild boar may cease breeding altogether in very poor mast years.

Overall mean litter size of 6.2 found in this study compared well with those reported from other studies of wild pigs. Giles (1980) reported a mean of 6.4 in Australia, Dzięciołowski (1991) 5.2 in Poland and Oloff (1951) reported 4.9 (60 litters) in Germany. Barrett (1978), Wood and Brenneman (1977), Henry (1968), and Pine and Gerdes (1973) reported mean litter sizes in feral pigs and wild boar in mainland USA to be 5.6,5.3, 4.9, and 4.6, respectively, based on numbers of litters ranging from 21 to 60 . Diong (1975) reported a mean of 4.5 piglets per litter in a sample of 12 wild boar females in Malaysia.

Differences between the average number of foetuses present and the average number of teats extended is believed to represent postnatal mortality of piglets. In this study this amounted to only 0.8 per litter, which suggests that an average of 5.4 piglets/litter survived the first $1-2$ months. Dzięciołowski (1991) found the following reduction of the mean litter size: summer -5.4 , autumn -4.5 , winter 4.0 piglets per average sow.

The assumption that the numbers of surviving piglets can be estimated from the number of suckled teats is based on an understanding that each piglet quickly assumes an exclusive use of a single teat and will defend the teat against other piglets until weaned (Day 1962, Pavlov 1980). Elsewhere it has been recorded that during periods of food shortage the sow's mammae successively dry up, leading to sequential mortality of the piglets (Fraser and Morley 1975). However, in this study area food was abundant and pigs were healthy and in good condition (Dzięciołowski and Clarke 19S6́): Accordingly, hunting mor tality would have been much greater than natural mortality.

Litter size in domestic pigs increases with age of sow up to the fourth litter and an increase in litter size with age up to three years was noted in feral pigs (Giles 1980) and in wild boars (Andrzejewski and Jezierski 1978). According to Andrzejewski and Jezierski (1978) $2-3$ years old sows have on average 3.4 piglets, $4-5$ years old ones -4.0 , while $6-7$ years old sows -5.0 piglets.

The models simulating various intensities of control (Fig. 5) suggest that high proportions of pig populations have to be removed before a reduction can be maintained for even a short length of time. Our estimate of a $70 \%$ instantaneous kill affording a reduction in numbers for 30 months is specific to heavily hunted populations of feral pigs in New Zealand. This predicted recovery time takes no account of immigration and uses a conservative value for $\Theta$ and is therefore probably a conservative estimate. However, Giles (1976) considered that a kill of about $70 \%$ was necessary to reduce feral pig abundance for over 12 months in Australia and other Australian workers (Hone and Robards 1980) have shown by modelling pig dynamics and control that annual control programmes each having 
a $70 \%$ instantaneous kill can significantly lower numbers in 3-4 years. In New Zealand however, hunting substantially reduces the rate of population recovery; survival of adult animals is low despite good breeding success.

Our findings have direct management implications for pig control operations in New Zealand where planning is in progress to control and eventually eliminate non-hunted pigs from offshore island fauna and flora reserves. For eradication, any primary control technique should ideally have the ability to remove $90-95 \%$ of pigs with subsequent rapid secondary treatment to remove survivors. For allievating pig impacts on important conservation areas on the New Zealand mainland lower percentage kills are probably more appropriate and achievable by means of additional ongoing hunting by the public. Because the assumptions used in the model were largely conservative, recovery times may be over-estimated. This, and the high capacity of pig populations for recovery, suggests that control of pigs in New 7ealand may have to rely on a range of control methods to achieve the desired reduction in feral pig abundance. McIlroy and Saillard (1989) have pointed to the usefulness of hunting with dogs for killing pigs that have survived poisoning campaigns. Similarly, C. M. H. Clarke (unpubl.) found specialist dog packs very effective for auditing pig bait and toxin acceptance trials and further noted their usefulness for intensive pig control and eradication. Further research and planning is required on integrated methods of control to ensure that future pig control exercises will be effective.

Acknowledgements: Authors wish to thank the Forest Research Institute in Christchurch, New Zealand for funding the project. The support of hunters is also gratefully acknowledged. Authors thank Prof. I. L. Brisbin for his constructive review of the paper.

\section{References}

Andrzejewski R. and Jezierski W. 1978. Management of a wild boar population and its effect on commercial land. Acta theriol. 23, 19: $309-339$.

Asdell S. A. 1964. Patterns of mammalian reproduction. 2nd ed., Ithaca, N.Y., Comstock Publishing Co.: $1-640$.

Barlow N. D. and Clout M. N. 1983. A comparison of 3-parameter, single-species population models, in relation to the management of brushtail possums in New Zealand. Oecologia 60: 250 - 258 .

Barrett R. H. 1978. The feral hog on the Dye Creek Ranch, California. Hilgardia, 46: $282-346$.

Bauer J. J. 1982. Untersuchungen zur Dynamik von stabilen und kolonisierenden Gemsenpopulationen (Rupicapra rupicapra L.) Neuseelands. Unpublished Ph.D. thesis. Albert-LudwigsUniversitat, Freiburg, Germany.

Briedermann L. 1971. Ermittlungen zur Aktivitatsperiodik des Mitteleuropaischen Wildschweine (Sus s. scrofa). Zool. Garten 10, 6: $302-327$.

Clarke C. M. H. 1991. Pig hunters and their dogs in the northern South Island: characteristics and harvest efficiency. New Zealand Geographer 47: $11-18$.

Clarke C. M. H. and Dzięciołowski R. M. 1991. Feral pigs in the northern South Island: 1. Origin, distribution and density. J.of the Royal Society of New Zealand 21: $237-247$. 
Clarke C. M. H., Dzięciołowski R. M., Batcheler D. and Frampton R. M. (in press). A comparison of tooth eruption and wear and dental cementum techniques in age determination of New Zealand feral pigs. J. of the Royal Society of New Zealand.

Day B. N. 1962. The reproduction of swine. [In: Reproduction in Farm Animals. E. S. E. Hafez, ed.]. Lea and Febiger, Philadelphia.

Diong C. H. 1973. Studies of the Malayan wild pig in Perak and Jahore. Malayan Nature Journal 26: $120-151$.

Dzięciołowski R. M. 1991. Ecological niches of five big ungulates in a forest tract. Folia Forestalia Polonica, Series A - Forestry 33: 56 - 70.

Dzięciołowski R. M. and Clarke C. M. H. 1989. Age structure and sex ratio in a population of harvested feral pigs in New Zealand. Acta theriol. 34: 525 - 536.

Dzięciołowski R. M. and Clarke C. M. H. 1990. Physical condition and ectoparasite infestation of feral pigs in New Zealand. Acta theriol. 35: 299 - 309.

Dzięciołowski R. M., Clarke C. M. H. and Fredric B. J. 1990. Growth of feral pigs in New Zealand. Acta theriol. 35: $77-88$.

Fraser D. and Morley J. R. 1975. The "teat order" of suckling pigs. I. Relation to birth weight and subsequent growth. J. Agric. Sci. Camb. 84: 387 - 391.

Giffin J. 1977. Ecology of the feral pig on Hawaii Island. Elepaio 37: 140 - 142.

Giffin J. 1978. Ecology of the feral pig on the island of Hawaii. Department of Land and Natural Resources, Division of Fish and Game, Hawaii: $1-121$.

Giles J. R. 1976. Feral pigs and Agriculture. [In: Conflict and Existence? Proc. Workshop Agric. For. Wildl.]. University of New England, Armidale, 1975: 125 - 128.

Giles J. R. 1980. The ecology of feral pigs in western New South Wales. Unpublished Ph.D. thesis, Sydney University.

Gilpen M. E., Case T. J. and Ayala F. J. 1976. Ө-selection. Math. Biosci. 32: 131 - 139.

Henry V. C. 1968. Length of estrous cycles and gestation in European wild hogs. J. Wildl. Manage. 32: $406-408$.

Hone J. and Robards G. E. 1980. Feral pigs: ecology and control. Wool Technol. Sheep Breed 28, 4: $7-11$.

Krupka J. (ed.) 1989. Lowiectwo. PWRiL - State Publ. for Agric. \& Forestry, Warszawa: 1 - 528.

Leslie P. H. 1945. On the uses of matrices in certain population mathematics. Biometrika 33: $183-212$.

McIlroy J. C. 1989. Aspects of the ecology of feral pigs (Sus scrofa) in the Murchison area. New Zealand J. Ecology 12: $11-22$.

McIlroy J. C. 1990. Feral pig. [In: The mammals of New Zealand. C. King, ed.]. Oxford University Press: $1-600$.

McIlroy J. C. and Saillard R. J. 1989. The effect of hunting with dogs on the numbers and movements of feral pigs, Sus scrofa, and the subsequent success of poisoning exercises in Namadgi National Park, A.C.T. Austr. Wildl. Res. 16: $353-363$.

Oloff H. B. 1951. Zur Biologie und Ökologie des Schwarzwildes. Dr Paul Schops Verlag: 1 - 95.

Pavlov P. M. 1980. The diet and ecology of the feral pig (Sus scrofa) at Girilambone, New South Wales. Unpublished Ph.D. thesis, Monash University, Melbourne.

Pine D. and Gerdes G. 1973. Wildpigs in Monterey County, California. Cal. Fish Game 59: 126 - 137.

Rathore A. K. 1988. Feral pig management programme - Blue Mountains District. Unpublished report, series 1. New South Wales National Parks and Wildlife Service: $1-36$.

Smiet A. C., Fulk G. W. and Lathiya S. B. 1979. Wild boar ecology in Thatta district: a preliminary study. Pakistan J. Zool. 11: 295 - 302.

Stubbe M. and Stubbe W. 1977. Vergleichende Beiträge zur Reproduktions- und Geburtsbiologie von Wild- und Hausschwein Sus scrofa L., 1758. Beitr. Jagd u. Wildforsch. 10: 153 - 179.

Sweeney J. M., Sweeney J. R. and Provost E. E. 1979. Reproductive biology of a feral hog population. J. Wildl. Manage. 43: 555 - 559 . 
Wodzicki K. A. 1950. Introduced mammals in New Zealand, an ecological and economic survey. N.Z. Department of Science and Industrial Research 98: 1-255.

Wood G. and Brennemany R. 1980. Feral hog movements and habitat use in coastal South Carolina. J. Wildl. Manage. 44, 4: $420-427$.

Received 20 March 1991, revised 16 July 1991, accepted 15 July 1992.

Acta Theriologica 37 (3): 270, 1992.

\section{BOOK REVIEW}

\section{Mammals of the Palaearetic Deserts}

Mammals of the Palaearctic desert: status and trends in the Sahara-Gobian region. J. A. McNeely and V. M. Neronov, eds. The Russian Academy of Sciences, The Russian Committee for the UNESCO Programme on Man and Biosphere, Moscow, 1991, 297 pp. Available from: Russian MAB Committee, Fersman Str. 13, 117312 Moscow, Russia, Fax (7-095) 129-13-54. Price 20 USD.

The book is based on the papers presented at the symposium "The conservation of rare and endangered mammal species by the Biosphere Reserves network in the Sahara-Gobian desert region", organized in the frame of 5th International Theriological Congress, held in Rome, Italy, in August 1989. It contains 20 papers presented at the meeting, divided in two parts. Frist one covers the discussion of general problems ( 8 papers) and the second presents case studies and national reports. The development of protected areas and conservation of rare species of mammals in the Sahara-Gobian desert region is evaluated. Elements of the conservation strategy for particular species in this region are proposed, including genetical background for the preservation of biological diversity. Both wild and endangered breeds of domestic mammals are discussed, as well as the influence of climate on distribution and evolution of desert mammals, their ecophysiological characteristics and impact (especialy of large herbivores) on the ecosystem. The second part contains some selected examples of data on the status and conservation of rare and endangered mammals in particular countries of the desert region.

Although not beeing complete, the book covers the main problems of conservation of rare and endangered species of mammals in the extensive belt of Palaearctic deserts and is a important source of information for students of mammals in this region. Both general ideas of the conservation strategy and relationships between mammals and their desert environment are of great importance for further studies and construction of action plans to conserve particular species. The role of Biosphere Reserve network already existing, but probably not sufficient to solve all problems of preservation the biodiversity of the region, is stressed in many papers. Some inconvenience to the reader is caused by abstracts which are lacking in many papers, or by placing tables and figures in the whole columns after the text, but not in appropriate places of the text.

The symposium and the publication of this book was a result of common efforts and financial support of the UNESCO Programme on "Man and Biosphere", the International Union of Biological Sciences, the World Conservation Union and the World Wide Fund for Nature (WWF). It seems, that those great international organizations could offer a little more financial support to get higher typographical standard of this interesting and valuable book.

Zdzisław PUCEK, Mammal Research Institute, Polish Academy of Sciences, 17-230 Białowieża, Poland 